\title{
SALINITY TOLERANCES OF THREE SPECIES OF FRESHWATER ATYID SHRIMPS (DECAPODA:CARIDEA) OF SRI LANKA
}

\author{
K. H. G. M. DE SILVA. \\ Department of Zoology, University of Peradeniya, Peradeniya, Sri Lanka.
}

(Date of receipt : 02 December 1986)

(Date of acceptance : 12 May 1987)

\begin{abstract}
Salinity tolerances of Caridina fernandoi, Caridina pristis and Caridina simoni were studied in the laboratory by subjecting individuals from three populations 'of each species to a graded series of concentrations of sea water. $C$. pristis showed the lowest salinity tolerance and $C$. simoni showed the highest salinity tolerance. The ultimate incipient lethal salinities (which just fail to kill $50 \%$ of the sample on indefinite exposure) of C. pristis, C. fermando $i$ and C. simoni appear to be about $10.5,13.5$ and $16.5 \mathrm{ppt} \mathrm{NaCl}$ respectively. The possible influence of the salinity tolerance on the geographic distribution of the three species is discussed.
\end{abstract}

\section{Introduction}

Atyids are an important component in the freshwater littoral fauna of tropics and subtropics and they appear to occupy a position similar to that occupied by isopods and amphipods in the temperate littoral fauna. Sri Lanka, although a small island of $65,600 \mathrm{~km}^{2}$, is rich in atyid fauna and contains ten species, which include Atya spinipes and nine species of Caridina. Of the nine species of Caridina, four, Caridina gracilirostris, Caridina propinqua, Caridina typus and Caridina zeylanica have a coastal distribution, two, Caridina fernando $i$ and Caridina simoni, are widely distributed at altitudes upto $700 \mathrm{~m}$, one, Caridina pristis, is found between 480 and $850 \mathrm{~m}$, one, the rare Caridina singhalensis, is isolated in a single stream at $2,100 \mathrm{~m}$, and one, Caridina costai, is reported only from one location at $500 \mathrm{~m} .{ }^{4}$ C. costai, C. fermandoi, C. pristis, C. singhalensis and C. zeylanica are not recorded outside Sri Lanka, except for a doubtful case of C. fernandoi in South India. ${ }^{14}$ C. pristis and C. singhalensis have a restricted distribution in the hill country and appear to be truly endemic to the island. Three species, namely, C. gracilirostris, C. propinqua and C. typus are widely distributed in the Indo-West Pacific region. ${ }^{1}$ Therefore it is interesting to know whether C. zeylanica, which is more widely distributed in the coastal region of Sri Lanka than the other three species, is truly confined to Sri Lanka. C. simoni, which occurs together with C. fernandoi, in many low country water bodies, is also widely spread in the Indo--west Pacific. ${ }^{1}$ Thus, it is also interesting to know whether $C$. fernando $i$ is also truly endemic. Since $C$. costai is recorded only from one location so far, more work is obviously necessary before the status of this species is decided. 
Despite the importance of Atyidae in the tropical freshwater ecosystem, not much attention has been paid to the group, except for the systematic studies, and little is known of the ecology of the group. Some preliminary work on the salinity tolerance of $C$. pristis and $C$. simoni. has been carried out. ${ }^{2,10}$ Apart from these, no work has been reported on the tolerance to ecological factors of Sri Lankan atyids. As part of a broader study of the distribution and ecology of Sri Lankan atyids, the present paper examines the role of salinity tolerance may play in determining the geographic distribution of three species, namely, C. fermandoi, C. pristis and C. simoni.

\section{Materials and Methods}

Samples of each species were collected from three populations. C. fernandoi was collected from Kandy lake, Kurunegala lake and a small reservoir at Ginigathena; C. pristis was collected from three slow-flowing streams at Peradeniya university campus, Galaha and Talatuoya; C. simoni was collected from Sarasavi oya at Peradeniya campus, Kandy lake and Kospothu Oya at Galagedera (Figure 1). Samples were kept separately in pond water in the laboratory at $24^{\circ} \mathrm{C}$ for at least two weeks prior to experimentation in order to acclimatise the shrimps to laboratory conditions. Shrimps were fed with decaying leaves of Ficus religiosa (Family Moraceae), which were easily obtained and found to be readily acceptable to all three species. Under these cultureconditions the mortalities were negligible.

Individuals of $C$. fermando $i$ and $C$. simoni in the size range $15-17 \mathrm{~mm}$, and individuals of $C$. pristis in the size range $12-14 \mathrm{~mm}$ were selected for experimentation. These size ranges include medium-sized adults. Sexing of live Caridina spp. is difficult and therefore, in order to determine whether the response to salinity is different between males and females, a preliminary experiment was carried out in which the response of the two sexes were tested for 10 days at $25 \%, 50 \%, 75 \%$ and $100 \%$ sea water $(7.5,15.0,22.5$ and 30.0 ppt $\mathrm{NaCl}$ ). Ten males and ten females of each species ( $C$. fernandoi and $C$. simoni from the Kandy lake populations and $C$. pristis from the Peradeniya population) were selected from the suitable size ranges and were kept at test salinities. There were no deaths in 10 days at $25 \%$ and $50 \%$ sea water in any species but mortalities occurred at higher concentrations. (Figure 2). Wilcoxon's two sample test showed that there was no statistically significant difference $(P>0.01)$ between the responses of males and females of any of the three species to salinities equivalent to $75 \%$ and $100 \%$ sea water. Therefore, no attempt was made to separate sexes in the subsequent experiments; but, ovigerous females were excluded. 

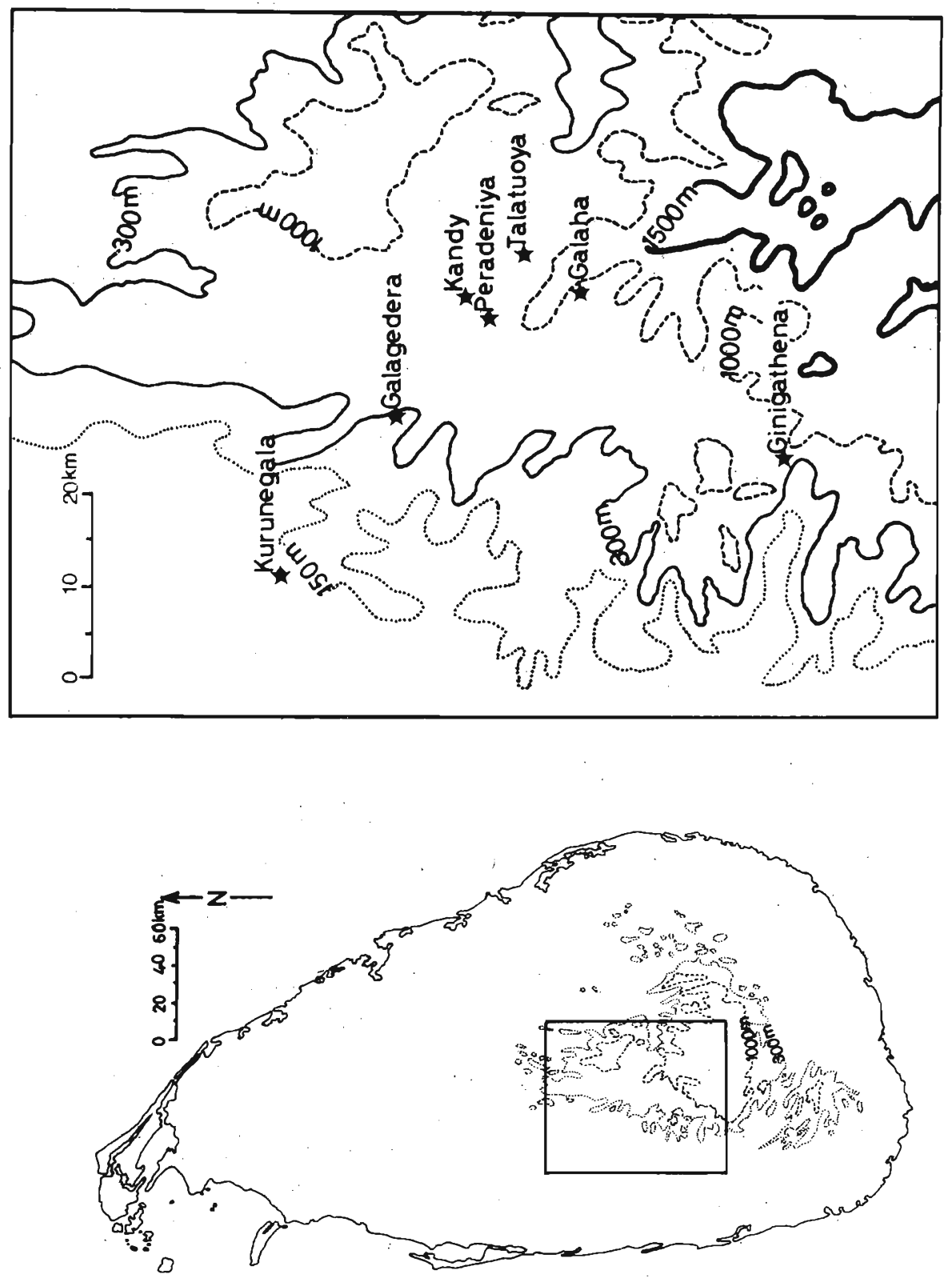

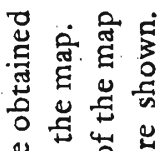
苟出岁苛 今ั 5 . 象施 瓷焉 क. 菏 $\dot{\Delta}$ 过

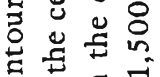
हैं

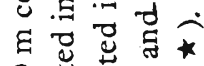
\&

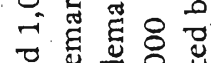

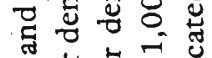
घ

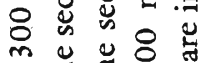

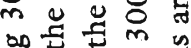
急.

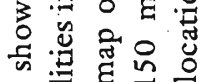

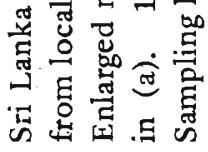
बิ 


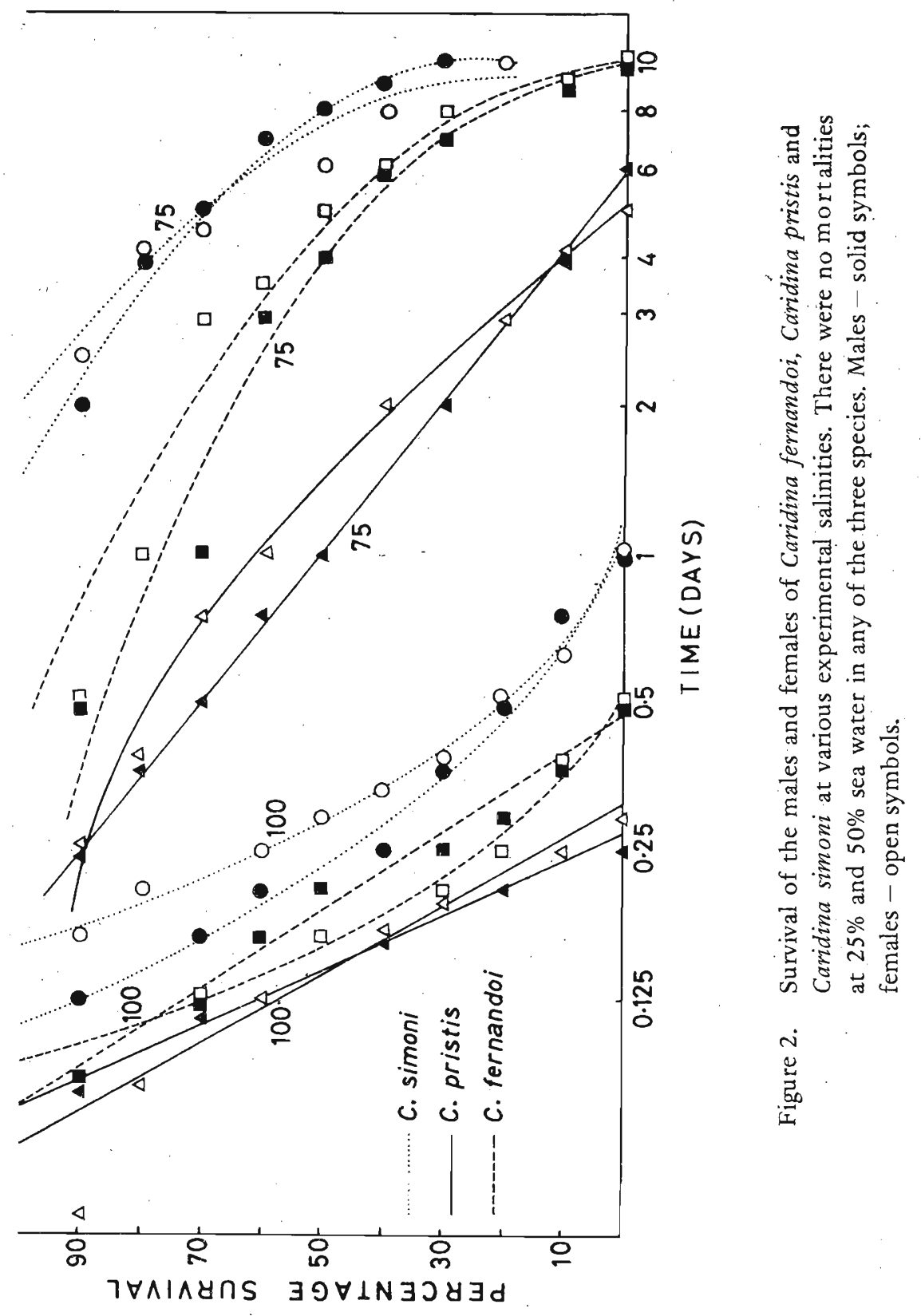


Thirty specimens (10 from each location) of each species were used in each experiment. Each specimen was kept in $100 \mathrm{ml}$ of the test medium in a wide-mouthed $250 \mathrm{ml}$ glass bottle (depth of water about $25 \mathrm{~mm}$ ). Pieces of decaying leaves of $F$. religiosa were provided as food. Experiments were carried out at salinities equivalent to $5 \%, 10 \%, 20 \%, 30 \%, 40 \%, 50 \%, 60 \%$, $70 \%, 80 \%, 90 \%, 100 \%$ and $110 \%$ sea water. The solutions upto $90 \%$ sea water were prepared by diluting sea water (salinity $30 \mathrm{ppt} \mathrm{NaCl}$ ) with pond water (zero salinity). By freezing out some of the water from $100 \%$ sea water a $110 \%$ solution was prepared. Sea water was stored in an opaque container for about a month before using. Controls were'kept in pond water. All experiments were carried out at $24^{\circ} \mathrm{C}$. Each individual was examined every hour for the first twelve hours, at 18 and 24 hours, and at 12 hourly intervals thereafter, and dead animals were counted and removed. A shrimp was considered dead when the movement of all appendages was completely stopped and would not resume under gentle probing. The medium in each container was renewed every two days with fresh medium of appropriate salinity. Each experiment was terminated on the 31st day, if not concluded carlier owing to $100 \%$ mortalities. These experiments were carried out during the period February-April, 1985.

\section{Results}

The mean survival rates of individuals from the three populations within each specics did not differ significantly at any experimental salinity in Kruskal-Wallis one way analysis. Therefore, results from all populations were pooled for each species.

The percentage survival times of C. fernandoi, C. pristis and C. simoni at various salinities are shown in Figures 3,4 and 5 . There were no mortalities during the 30 day period upto $40 \%$ sea water (12 ppt $\mathrm{NaCl}$ ) in C. fermandoi and C. simoni, and upto $20 \%$ sea water in C. pristis. $70 \%$ and $87 \%$ of $C$. pristis survived the 30 day period at $40 \%$ and $30 \%$ sea water. The percentage survival of C. simoni, C. fermandoi and C. pristis at the end of 30 day period at $60 \%$ sea water were $67 \%, 40 \%$ and $10 \%$ respectively, and at $50 \%$ sea water were $85 \%, 80 \%$ and $55 \%$ respectively, and the median survival times (MST) of the three species at $60 \%$ sea water were $30,21.5$ and 8 days respectively. These observations indicate that $C$. simoni has the highest salinity tolerance and C. pristis has the least salinity tolerance. Results from experiments conducted at other salinities confirm this (Table 1).

Although the ultimate incipient lethal salinities (ILS) (i.e. the lethal salinity levels which on indefinite exposure just fail to kill $50 \%$ of the sample) of the three species cannot be determined precisely from the present data, a rough estimate can be made from the probit lines in Figures 3, 4 and 5 , and from the MST graphs in Figure 6. The ILSs of $C$. pristis, C. fermandoi 


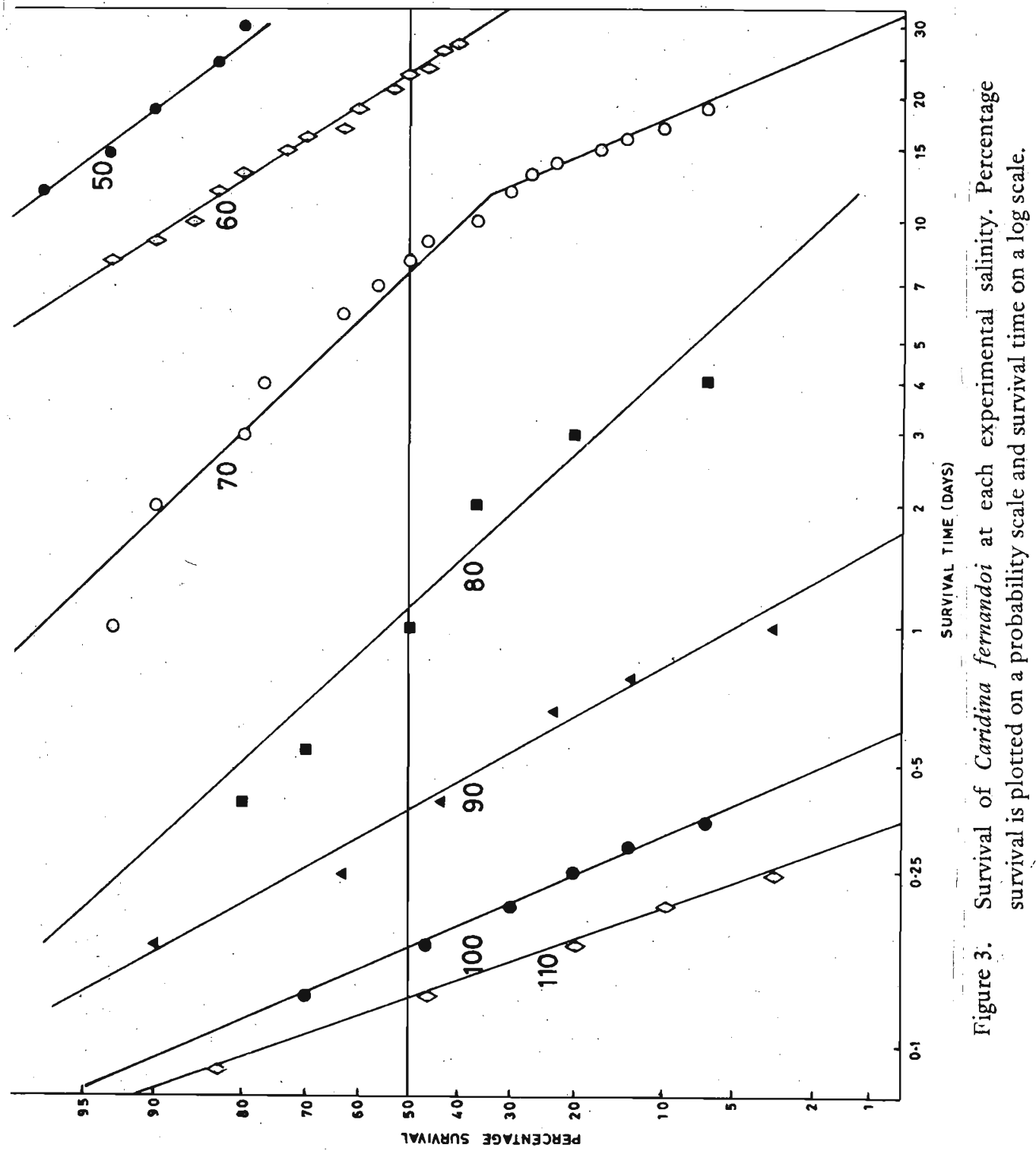




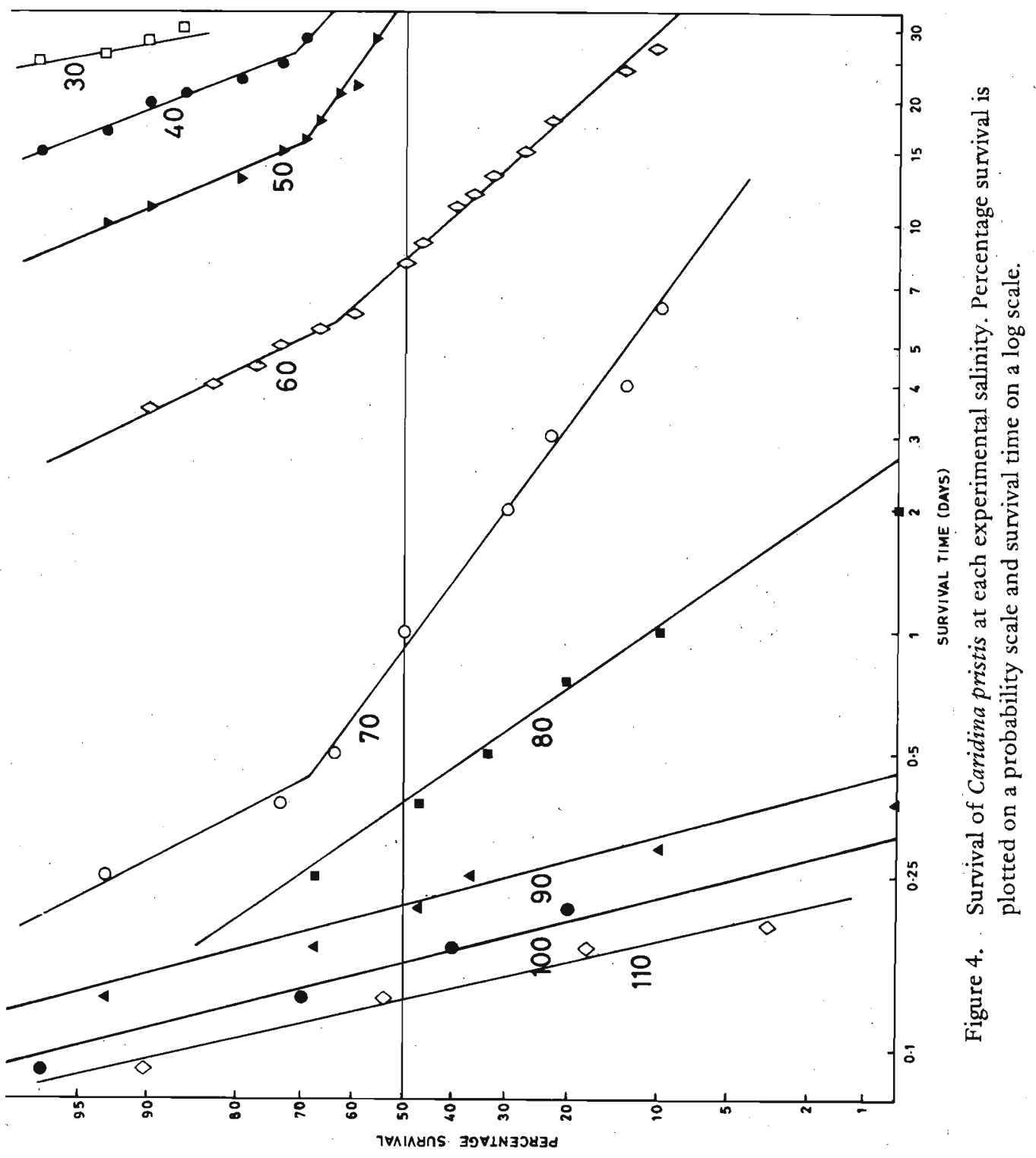




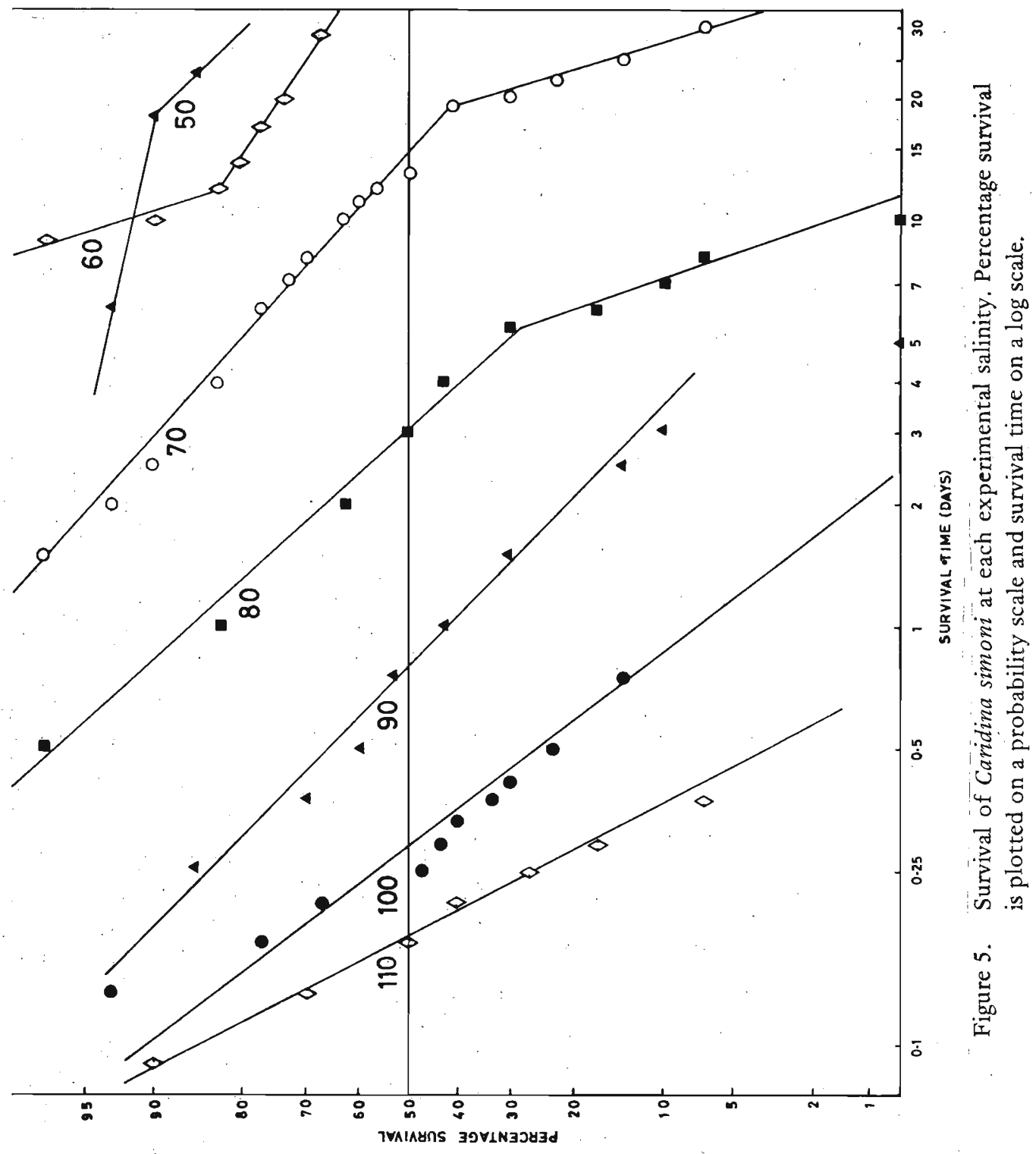




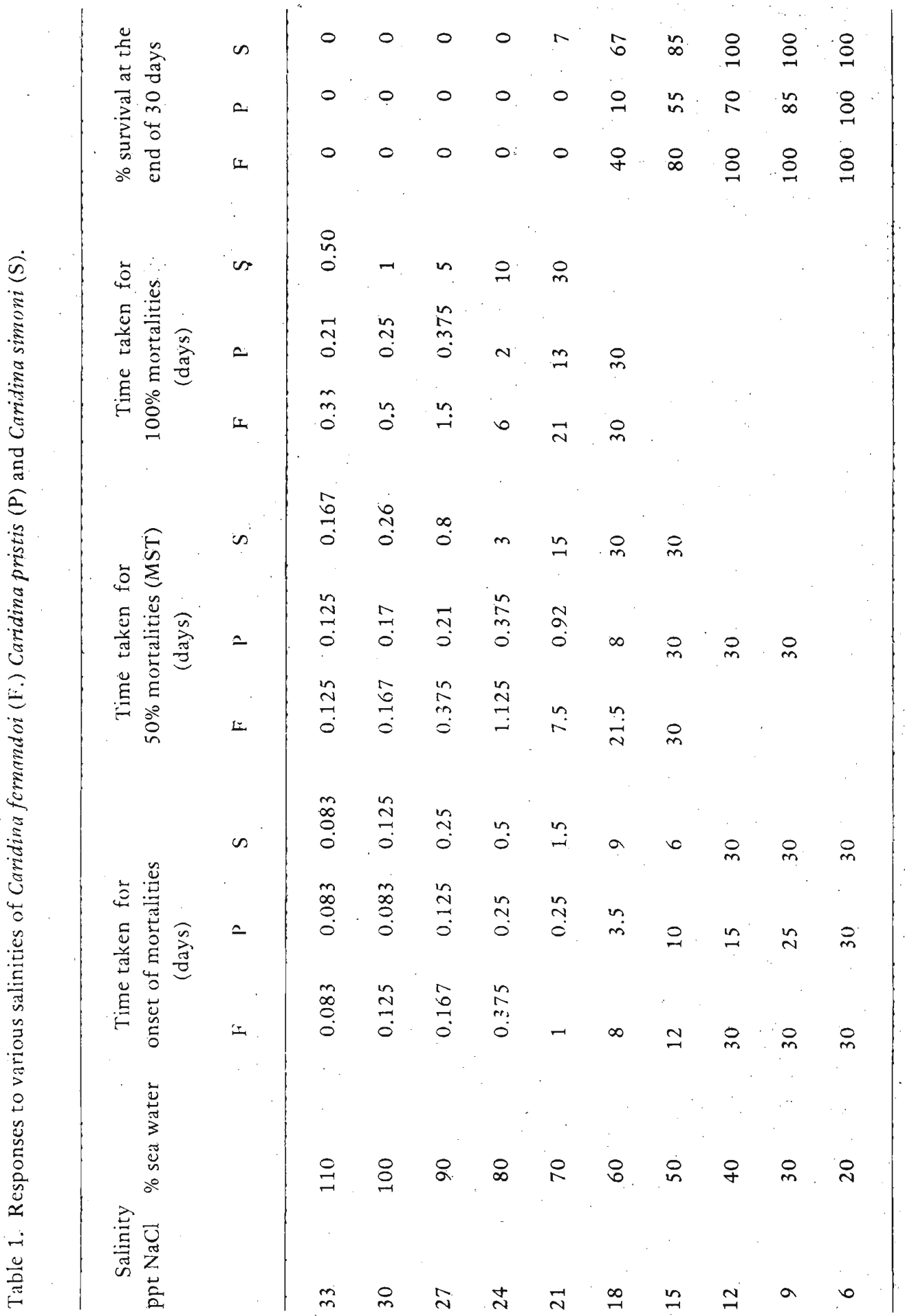




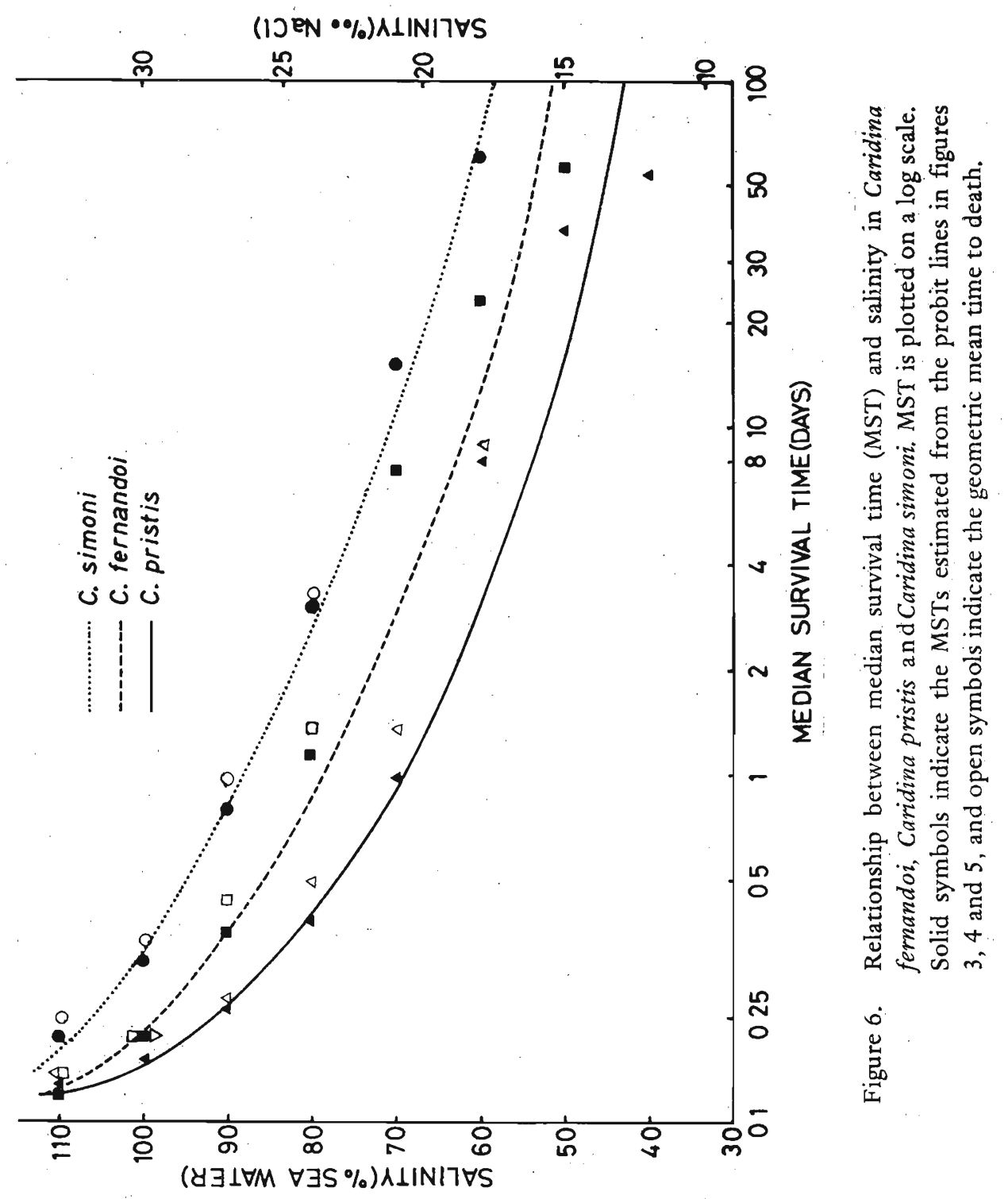


and $C$. simoni thus estimated appear to be $35 \%, 45 \%$ and $55 \%$ sea water $(10.5,13.5$ and $16.5 \mathrm{ppt} \mathrm{NaCl})$ respectively.

\section{Discussion}

The results indicate that all three species can live in low salinity brackish water. However, C. pristis has not been recorded below an altitude of $480 \mathrm{~m}$. Therefore, other ecological factors must be responsible for limiting the species to upper elevations. The data on its response to various temperatures indicate that temperature is of major importance in this respect. ${ }^{5}$ C. pristis also has the lowest salinity tolerance of the three species, with MSTs of $>30$ days, 8 days and less than 1 day at $15 \mathrm{ppt}, 18 \mathrm{ppt}$ and $21 \mathrm{ppt} \mathrm{NaCl}$ respectively. Because of its confinement to upper elevations and its low salinity and high temperature tolerances, it does not appear to be amenable to a marine distribution and hence it is unlikely to find $C$. pristis outside Sri Lanka, if it had evolved within the island.

C. fernando $i$ has MS'Ts of $>30$ days, 21.5 days and 7.5 days at salinities of $15 \mathrm{ppt}, 18 \mathrm{ppt}$ and $21 \mathrm{ppt} \mathrm{NaCl}$ respectively. It is found almost down to the sea level. For instance, it has been recorded from Giant's reservoir at Murunkan ${ }^{6}$ at less than $10 \mathrm{~m}$ altitude. However, it has not been recorded from brackish water. Responses of $C$. fermando $i$ to various temperatures and $\mathrm{pHs}^{5}$ indicate that these factors are of no hindrance for the species to colonize at least some of the low salinity brackish water bodies or inland water bodies that become somewhat saline during some part of the year. Thus, the possibility exists that its range of geographic distribution is wider than presently known and extends outside Sri Lanka. In this connection, it is of importance to note that $C$. simoni, with which $C$. fermandoi occur in many water bodies, is widely distributed in the Indo-West Pacific.

C. simoni shows the highest salinity tolerance among the three species, with MSTs of $>30$ days at 15 and $1.8 \mathrm{ppt}$, and 15 days at $21 \mathrm{ppt} \mathrm{NaCl}$. It has been recorded from slightly brackish water bodies in Sri Lanka, for instance, at $0.15 \mathrm{ppt} \mathrm{NaCl}$ at Beira $\mathrm{Lake}^{3}$ and at the same salinity at Bolgoda lake. ${ }^{5}$ Its wide distribution in the IndozWest Pacific includes many islands in the Pacific. ${ }^{8}$ (The taxonomic status of C. simoni is still not settled and some authors ${ }^{7}$ consider it as conspecific with $C$. nilotica, a species found in East Africa from Egypt to Natal. ${ }^{7}$ ) It has been described as occasionally occurring in slightly brackish waters ${ }^{7}$ and entering low salinity tidal rivers. ${ }^{8}$ Its pattern of distribution and the ability to tolerate considerable salinity suggest that it is capable of some marine dispersal.

In some Caridea, even though the adult may be purely freshwater, the larva may have a salt water requirement for development (e.g. Atya spp. and Macrobrachium spp.). Thus, presumably, larva of these species has a higher 
salinity tolerance than the adult and the larva may be capable of marine dispersal. ${ }^{9}$ No data are available on this aspect of the three species considered in the present study, except for the observation that there is no brackish water requirement for the development of the larva of all three species $^{5}$ and that $C$. simoni could apparently develop in slightly brackish waters.

In an earlier study, ${ }^{2}$ C. simoni, when offered a choice between diluted sea water and tap water, reacted indifferently to the two media upto 16.5 ppt $\mathrm{NaCl}$ at $25^{\circ}-26^{\circ} \mathrm{C}$ (the shrimp's response to higher salinities were not tested). This is in agreement with the present results since the MSTs at 15 at $18 \mathrm{ppt} \mathrm{NaCl}$ were more than 30 days. However, in another study of salinity tolerance of this species, ${ }^{10} 30 \%$ and $40 \%$ mortalities occurred in $>30$ days at $3 \mathrm{ppt}$ and $6 \mathrm{ppt} \mathrm{NaCl}$ respectively at $24^{\circ}-26^{\circ}$, and the MST at $11 \mathrm{pt}$ was 22 days, in contrast to the absence of mortalities upto $12 \mathrm{ppt}$ during the same period and a MST of more than 30 days even at $18 \mathrm{ppt}$ observed in the present study (Table 1). The observations on the salinity response of $C$. pristis in the present study differ markedly from those of the two earlier studies. ${ }^{2}, 10$ It was shown that there was a negative reaction even at $6 \mathrm{ppt} \mathrm{NaCl}, 2$ and that the MSTs at 3, 6 and $9 \mathrm{ppt} \mathrm{NaCl}$ were 24 days, 23 days and 21 days respectively, ${ }^{10}$ in contrast to the absence of mortalities upto 6 ppt and $13 \%$ and $30 \%$ mortalities in $>30$ days at 9 and $12 \mathrm{ppt}$ respectively observed in the present study. It is difficult to account for the differences observed, since experiments were carried out at similar temperatures and using specimens presumably from the same locality at Peradeniya. However, it is not clear from the description of the earlier experiments 10 . whether, (i) shrimps were acclimatised to laboratory conditions prior to experimentation, (ii) food was provided to the shrimps during the experimental period, and (iii) all specimens used in experiments belonged to the same size class, and if so, which size class was used. In this earlier study, 10 20 shrimps were kept in a single container (size of the container and the amount of medium used not specified) and therefore, the possibility of dead and decaying shrimps contaminating the medium and affecting the condition of the live ones cannot be ruled out, since the observations were made only once a day and the medium was changed only $2-4$ days. It was noted that even a few dead and decaying shrimps could contaminate and cause considerable mortalities in cultures within a few hours.

Salinity response of a species may change with the ambient temperature. Although data are lacking for atyids, it is known that in estuarine decapods such as fiddler crabs (Uca spp.), tolerance to high salinities decreases with increase of temperature. ${ }^{11}$ Thus, it is possible that the ranges of salinity tolerance of the three species are different at the temperatures prevalent at the sea level than those estimated in the present study at $24^{\circ} \mathrm{C}$. The monthly mean temperature of Beira lake varied between $26^{\circ}$ and $33^{\circ} \mathrm{C}$ during the period May 1969 to March $1971^{3}$ and that of Bolgoda lake varied 
between $28^{\circ}$ and $32^{\circ} \mathrm{C}$ during the period October 1980 to September $1981 .{ }^{13}$ It has also been shown that, in species such as Uca spp., exposure to sublethal intensities of two environmental factors such as temperature and salinity could become lethal. ${ }^{12}$. The organism interacts not with individual ecological factors but with the sum total of many separate factors, and these factors may act synergetically to produce an effect which is more extreme than that which results when each factor acts separately. Thus, study of synergetic action of at least temperature and salinity is more appropriate for understanding geographic distribution of atyid species.

\section{Acknowledgements}

Thanks are due to Mr. T.S.B. Alagoda of this department for drawing the figures in this paper. I also wish to thank my wife, Kumari, for her unfailing help both in the field work and laboratory work. This work was carried out in the laboratories of Department of Zoology, University of Peradeniya.

\section{References}

1. BOUVIER, E.-L. (1925) Encyclopedie Entomologique, 4: 1-370.

2. COSTA, H. H. (1966) Ceylon J. Sci. (Bio. Sci.), 6(1): 33-36.

3. COSTA, H. H. \& DE SILVA, S. S. (1978) Spolia Zeylan. 32(2): 19-81.

4. DE SILVA, K. H. G. M. (1983)Crustaceana, 44(2): 205-215.

5. DE SILVA, K. H. G. M. unpublished data.

6. FERNANDO, C. H. (1965) Bull. Fish. Res. Stn. Ceylon, 18: 17-29.

7. HOLTHUIS, L. B. (1980) FAO species catalogue. Vol. 1. Shrimps and prawns of the world, 74 p. Rome: FAO.

8. JOHNSON, D. S. (1963) Bull. National Mus. Singapore, 32: 5-30.

9. JOHNSON, D. S. (1966) Proc. Symp. Crustacea, I. Ernakulam, India. 418-433.

10. PERERA, N. B. A. (1966) Ceylon J. Sci. (Bio. Sci.), 6(1): 15-19.

11. VERNBERG, F. J. \& VERNBERG, W. B. (1975) In: VERNBERG, F. J. (ed.) Physiological ecology of estuarine organisms. Univ. S. Carolina Press. 165-180. 
12. VERnBerG, W. B., DeCOURSEY, P. J. \& PAdGetT, W. J. (1974) Marine Biol. 22: 307-312.

13. WIGNARAJAH, S. \& AMARASIRIWARDENA, P. (1983) J. Natn. Sci. Coun. Sri Lanka, 11(2): 255-268.

14. WYCLIFFE, M. J. \& JOB, S. V. (1977) Hydrobiologia, 54: 33-39. 